\title{
PENYELIDIKAN KEBOCORAN PIPA BAWAH TANAH MENGGUNAKAN METODE GEOLISTRIK KONFIGURASI WENNER-SCHLUMBERGER BERDASARKAN MODEL FISIS SKALA LABORATORIUM
}

\author{
Dodi Irwan Siregar ${ }^{1, *}$, Juandi $\mathbf{M}^{2}$, Mhd Edisar ${ }^{2}$ \\ ${ }^{1}$ STIE Persada Bunda J1. Diponegoro Pekanbaru \\ ${ }^{2}$ Dosen Jurusan Fisika \\ Fakultas Matematika dan Ilmu Pengetahuan Alam \\ Universitas Riau Pekanbaru \\ Kampus Bina Widya Jl. Prof. Dr. Muchtar Luthfi \\ Panam Pekanbaru 28282 \\ *E-mail : dodi.irwan.siregar@gmail.com
}

\begin{abstract}
The research has been done using physical modeling of geoelectric configuration application of WennerSclumberger to model the existence of underground pipe leakage. Modeling is done on a tub made of wood and glass which is filled with sand and clay as medium (host-rock) and the inclusion of leaked steel pipe, the first measurement model is done before the fluid flow into the leaking pipe, obtained the type of pipe resistance pattern $2310 \quad m$ at a depth of $25 \mathrm{~cm}$ from the sand surface with an error iteration of $9.5 \%$. The second model is measured by flowing water into the leaking pipe obtained the pattern of resistance around the type of leakage where the leak is lower is between $6.49-55.9 \mathrm{~m}$ lies in the horizontal range $12.5-20.5 \mathrm{~cm}$ and in the vertical range $10-45 \mathrm{~cm}$ from the sand surface with $25.8 \%$ error iteration. The third model is measured by flowing kerosene into leaking pipe can be seen clearly the pattern of distribution of resistance type around the leaky pipe is lower $12-71.3 \mathrm{~m}$ lies in the horizontal range $11-19 \mathrm{~cm}$ and in the vertical range of 7-25 $\mathrm{cm}$ from the surface sand with $15.7 \%$ error iteration.
\end{abstract}

Keywords: Underground Pipe, Geolistrik, Physics Modeling, Wenner-schlumberger configuration electrode.

\begin{abstract}
ABSTRAK
Penelitian ini dilakukan dengan menggunakan pemodelan fisik aplikasi konfigurasi geoelektrik WennerSclumberger untuk memodelkan keberadaan kebocoran pipa bawah tanah. Pemodelan dilakukan pada bak yang terbuat dari kayu dan kaca yang diisi dengan pasir dan tanah liat sebagai media (host-rock) dan penyertaan pipa baja bocor, model pengukuran pertama dilakukan sebelum aliran fluida ke pipa bocor, diperoleh jenis pola resistansi pipa 2310 m pada kedalaman $25 \mathrm{~cm}$ dari permukaan pasir dengan iterasi kesalahan sebesar 9,5\%. Model kedua diukur dengan mengalirkan air ke dalam pipa bocor yang diperoleh pola resistansi sekitar jenis kebocoran dimana kebocoran lebih rendah antara 6,49 - 55,9 m terletak pada kisaran horizontal 12,5 $20,5 \mathrm{~cm}$ dan pada rentang vertikal 10 - 45. cm dari permukaan pasir dengan iterasi kesalahan 25,8\%. Model ketiga yang diukur dengan mengalirkan minyak tanah ke dalam pipa bocor dapat dilihat dengan jelas pola distribusi tipe resistansi di sekitar pipa bocor yang rendah 12 - 71,3 m terletak pada kisaran horisontal 11 $19 \mathrm{~cm}$ dan pada rentang vertikal 7-25. cm dari pasir permukaan dengan iterasi kesalahan 15,7\%.
\end{abstract}

Kata kunci: Pipa Bawah Tanah, Geolistrik, Pemodelan Fisika, konfigurasi elektroda Wenner-schlumberger.

\section{PENDAHULUAN}

Akhir-akhir ini maraknya kebocoran pipa bawah tanah yang terjadi karena faktor korosi, kerusakan disebabkan oleh faktor lain, ataupun pencurian yang dilakukan oleh oknum tertentu (Illegal Tapping), hal ini menyebabkan banyaknya kerusakan dan kerugian, baik itu dilihat dari sisi lingkungan, ekonomi, maupun sosial-budaya. Penanaman pipa bawah tanah yang dilakukan oleh perusahaan-perusahaan dan instansi-instansi baik yang dimiliki oleh pihak pemerintah maupun swasta untuk menyuplai berbagai jenis keperluan. Mulai dari pipa 
minyak, pipa air, dan pipa lainnya, semua itu memerlukan pengawasan dan pemeliharaan yang berkelanjutan.

Penulis tertarik untuk melakukan penelitian mengenai penyelidikan kebocoran pipa bawah tanah skala laboratorium dengan menggunakan metode geolistrik yaitu, metode geofisika yang mempelajari sifat-sifat listrik bebatuan. Tujuannya adalah mengukur harga resistivitas untuk mengapatkan sebaran tahanan jenis dibawah permukaan dengan melakukan pengukuran diatas permukaan. Juandi mengatakan besarnya nilai resistivitas permukaan ditentukan oleh mineral, komponen penyusun cairan, porositas dan derajat saturasi air didalam batuan, konfigurasi elektroda dalam pengukuran harga resistivitas bertujuan untuk memperoleh informasi tentang faktor geometri bumi, faktor geometri diturunkan dari beda potensial yang terjadi antara jarak elektroda [1].

\section{LANDASAN TEORI}

Metode resistivitas pada dasarnya adalah pengukuran harga resistivitas (tahanan jenis) tanah. Prinsip kerja metode ini adalah dengan menginjeksikan arus ke bawah permukaan bumi sehingga diperoleh beda potensial (Volt), yang kemudian akan didapat informasi mengenai tahanan jenis tanah. Untuk mengetahui harga tahanan jenis tanah yang akurat diperlukan pengukuran secara langsung pada lokasi, karena struktur tanah yang sesungguhnya tidak sesederhana yang diperkirakan, untuk setiap lokasi yang berbeda mempunyai hambatan jenis tanah yang tidak sama [2] Ilustrasi garis equipotensial yang terjadi akibat injeksi arus ditunjukkan pada dua titik arus yang berlawanan di permukaan bumi, seperti yang di lukiskan pada Gambar 1.

Persamaan nilai resistivitas / tahanan jenis adalah sebagai berikut :

$$
\rho=k \frac{V}{I}
$$

Keterangan :

$\rho=$ Resistivitas (Ohm.meter) $\mathrm{k}=$ Faktor Geometri Elektroda (meter)

$\mathrm{V}=$ Beda Potensial (Volt.meter)

$\mathrm{I}=$ Kuat Arus (Ampere.meter)

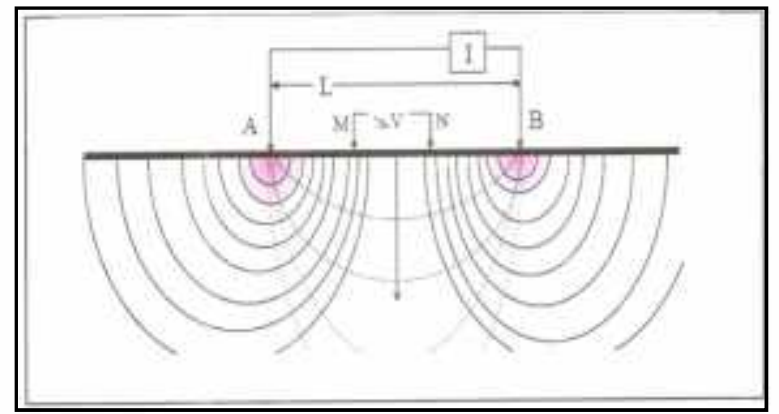

Gambar 1. Pola Aliran arus dan bidang equipotensial antara dua elektroda arus yang menimbulkan beda potensial diantara kedua elektroda tersebut.

Penelitian ini menggunakan konfigurasi Elektroda Wenner, penempatan elektrode arus dan elektrode potensial diletakkan seperti pada Gambar 2 sebagai berikut:

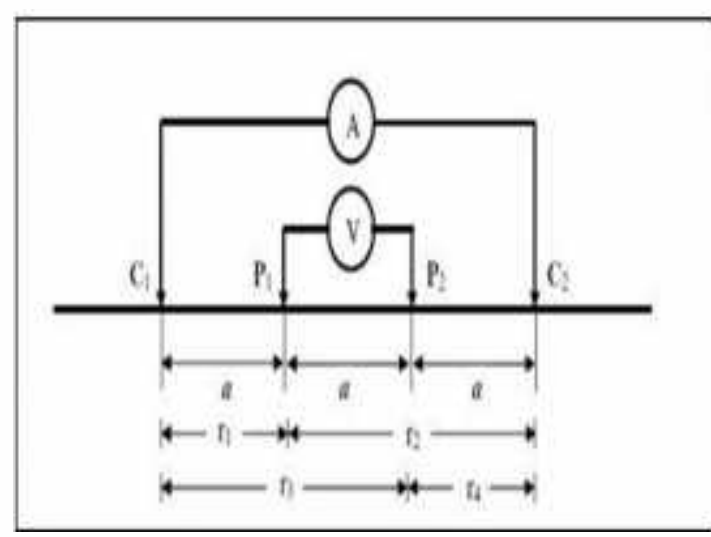

Gambar 2. Konfigurasi Elektroda Wenner.

Dalam hal ini, elektrode arus dan elektrode potensial mempunyai jarak yang sama yaitu $\mathrm{C} 1 \mathrm{P} 1=\mathrm{P} 1 \mathrm{P} 2=\mathrm{P} 2 \mathrm{C} 2=a$. Jadi jarak antar elektrode arus adalah tiga kali jarak antar elektrode potensial. Perlu diingat bahwa keempat elektrode dengan titik datum harus membentuk satu garis [3]. Dari Gambar 2 diatas, dapat diperoleh besarnya Faktor Geometri untuk Konfigurasi Wenner adalah sebagai berikut:

$$
k=2 \pi
$$

Sehingga pada konfigurasi Wenner berlaku hubungan:

$$
\rho=2 \pi a \frac{\Delta V}{t}
$$




\section{METODE PENELITIAN}

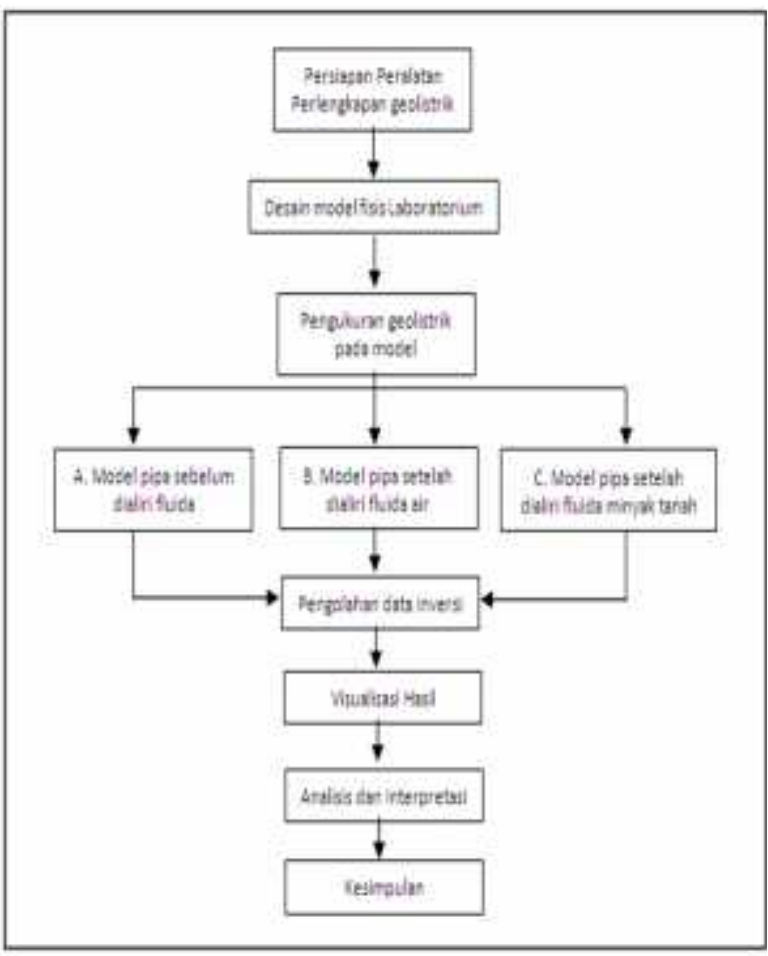

Gambar 3. Diagram alir (flow chart) penelitian.

Metode penelitian kali ini menggunakan metode eksperimen yang dilakukan di Labaoratorium Fisika Bumi Jurusan Fisika FMIPA UR dengan membuat desain model fisis menggunakan bak kayu dan kaca berbentuk balok dengan ukuran panjang 2 meter, lebar 0,5 meter dan tinggi 0,5 meter. Pemodelan fisis laboratorium dilakukan pada suatu bak yang berbentuk balok diisi dengan campuran pasir dan tanah liat sebagai host-rock dan dimasukkannya pipa besi yang telah dibocorkan sebagai ganti pipa sebenarnya.

Model pengukuran pertama dilakukan dengan tidak mengalirkan fluida, model pengukuran kedua dilakukan dengan mengalirkan fluida air kedalam pipa, dan model pengukuran ketiga dilakukan dengan mengalirkan minyak tanah kedalam pipa yang telah dibocorkan. Diagram alir (Flow Chart) penelitian seperti Gambar 2.

Kemudian masing-masing model didapat hasil pengukuran $\Delta V$ dan $\Delta l$. Pengolahan data inversi pada masing-masing model dapat dilakukan dengan menggunakan software RES2DINV sehingga didapat tampilan berupa gambar visuasisasi hasil pada setiap model, kemudian dianalisis dan Interpretasi dari hasil visualisasi yang didapat. Seperti Gambar 4 berikut :

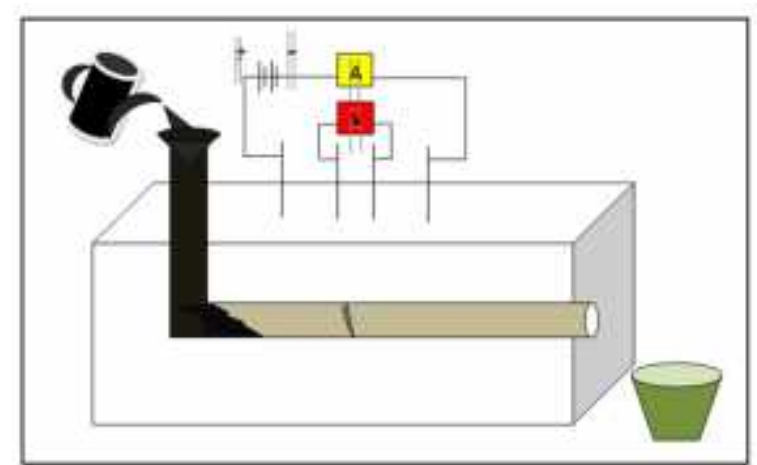

Gambar 4. Model fisis Laboratorium penelitian.

\section{HASIL DAN PEMBAHASAN}

Dari hasil pengukuran menggunakan alat Resistivity meter didapatkan harga Beda Potensial $(\Delta V)$ dan kuat arus listrik $(\Delta l)$ pada masing-masing model. Dengan menggunakan Software RES2DINV untuk mengolah data hasil pengukuran pada masing-masing model didapatkan visualisasi hasil.

\section{Pengukuran pipa bawah permukaan tanah yang belum dibocorkan.}

Gambar hasil pencitraan pipa bawah permukaan tanah menggunakan software adalah seperti Gambar 5 berikut :

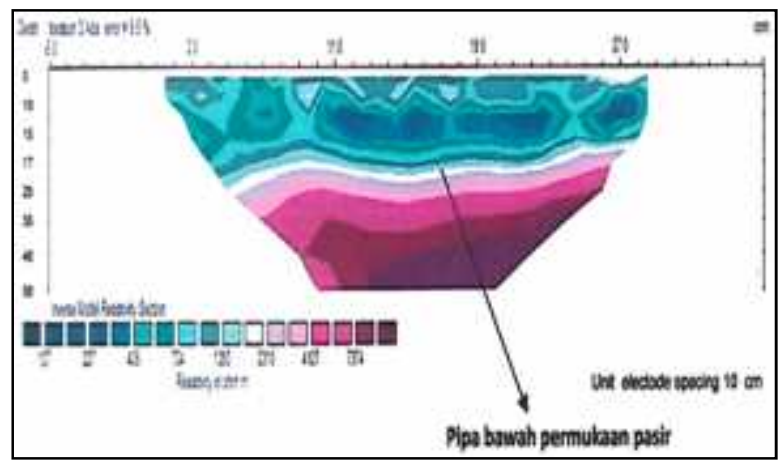

Gambar 5. Pengukuran hasil Inversi penampang tahanan jenis pipa bawah tanah skala laboratorium.

Penampang tahanan jenis pipa didalam permukaan pasir sebelum dialiri fluida dengan 
pengukuran menggunakan konfigurasi elektroda wenner-schlumberger didapat nilai resistivitas pipa didalam permukaan pasir sekitar (1851 $3865 \mathrm{~m})$ dengan kedalaman antara $25-35 \mathrm{~cm}$ dari permukaan dengan iterasi kesalahan 9,5\% .

\section{Pengukuran penampang tahanan jenis pipa yang telah dibocorkan dialiri oleh air skala laboratorium}

Hasil pengukuran penamgpang tahanan jenis pipa didalam permukaan pasir setelah dialiri air kedalam pipa yang sengaja dibocorkan, dari hasil inverse menggunakan software Res2dinv diperoleh penampang tahanan jenis pipa yang dialiri air seperti Gambar 6 berikut :

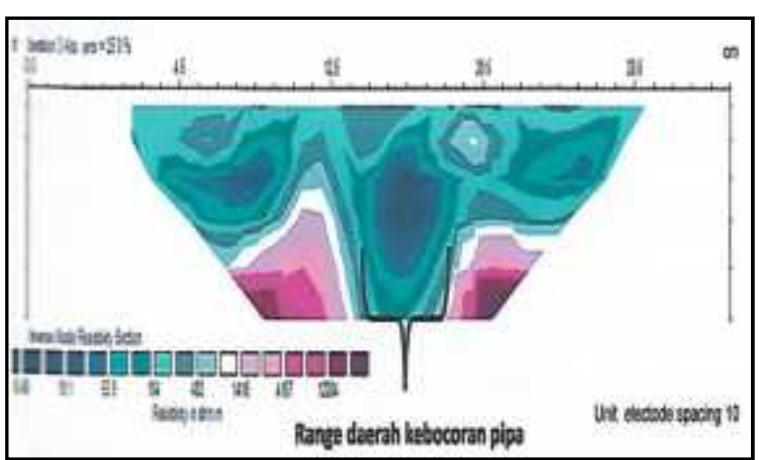

Gambar 6. Pengukuran hasil Inversi penampang tahanan jenis pipa air bawah tanah skala laboratorium.

Hasil inverse dari Gambar 5 dapat diinterpretasikan range kebocoran pipa bawah tanah skala laboratorium secara horizontal berada 12,5 - 20,5 cm dengan tahanan jenis 6,49 $-55,9$ m. Dengan iterasi kesalahan 25,8\% [4].

Pengukuran penampang tahanan jenis pipa yang telah dibocorkan dialiri oleh minyak tanah skala laboratorium

Hasil pengukuran penampang tahanan jenis pipa yang telah dibocorkan dialiri oleh minyak tanah ditunjukkan pada Gambar 7. Hasil interpretasi didapat kebocoran pipa bawah tanah yang telah dialiri minyak tanah adalah pada range $11-19 \mathrm{~cm}$, sedangkan tahanan jenis pada renge kebocoran tersebut berkisar antara 12 -
71,3 m [5]. Pada kedalaman 7 - $25 \mathrm{~cm}$ dari permukaan pasir dengan iterasi kesalahan $15,7 \%$.

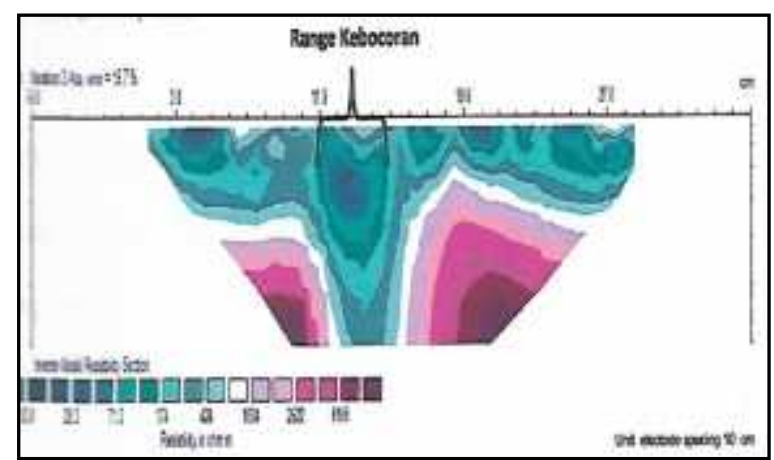

Gambar 7. Pengukuran hasil Inversi penampang tahanan jenis pipa dialiri minyak tanah skala laboratorium.

\section{KESIMPULAN}

Model pengukuran pertama dilakukan sebelum mengalirkan fluida kedalam pipa yang bocor didapatkan pola sebaran tahanan jenis pipa 2310 $m$ dengan iterasi kesalahan 9,5\% pada kedalaman $25 \mathrm{~cm}$ dari permukaan pasir. Model kedua dilakukan pengukuran dengan mengalirkan air kedalam pipa yang telah dibocorkan didapatkan pola sebaran tahanan jenis disekitar tempat yang bocor lebih rendah yaitu 6,49 - 55,9 $\mathrm{m}$ terletak pada range horizontal $12,5-20,5 \mathrm{~cm}$ dan range vertical yaitu pada kedalaman $10-45 \mathrm{~cm}$ permukaan pasir dengan iterasi kesalahan 25,8\%. Model ketiga dilakukan pengukuran dengan mengalirkan minyak tanah kedalam pipa yang telah dibocorkan didapatkan pola sebaran tahanan jenis disekitar tempat yang bocor lebih rendah yaitu $12-71,3$ m terletak pada range horizontal $11-19 \mathrm{~cm}$ dan range vertical yaitu pada kedalaman $7-25 \mathrm{~cm}$ permukaan pasir dengan iterasi kesalahan $15,7 \%$.

\section{SARAN}

Disarankan agar pengukuran geolistrik menggunakan konfigurasi elektroda yang lain dan menggunakan transformasi data agar mendapatkan nilai error yang lebih kecil lagi. 


\section{UCAPAN TERIMA KASIH}

Penulis mengucapkan terima kasih kepada kedua orang tua yaitu Bapak dan Mamak, Adekadek sekalian yang terus memberi semangat lahir dan batin kepada penulis, juga kepada teman-teman yang setia membantu penulis dalam penelitian ini, dan kepada seluruh pihak yang telah membantu penulis.

\section{DAFTAR PUSTAKA}

1. Juandi, M. (2011). Harga resistivitas untuk mengapatkan sebaran tahanan jenis dibawah permukaan. FMIPA UR, Pekanbaru.

2. Hutauruk, T. S. (1991). Pengentanahan netral sistem tenaga dan pengentanahan peralatan. Jakarta: Erlangga.
3. Dobrin, M. B. (1981). Introduction to geophysical prospecting. New York: McGraw-Hill.

4. Damayanti, T. (2011). Aplikasi geolistrik skala model untuk menentukan nilai resistivitas lapisan tanah yang mengalami pencemaran. Jurusan Fisika, Fakultas Matematika dan Ilmu Pengetahuan Alam Universitas Negeri Semarang (Unnes), Semarang, Indonesia.

5. Milsom, J. (2003). Field geophisics, The geological field guide series. England : West Sussex P019 8SQ. 